\title{
A Comparative Study of Laryngeal Mask Airway and Air-Q Intubating Laryngeal Airway Using Parker Flex Tip Tube
}

\author{
Sanjay Melville Masih ${ }^{1}$, Rakesh Kumar Gupta ${ }^{2}$ \\ ${ }^{1}$ Associate Professor, Department of Anaesthesiology, FH Medical College, Tundla, India, ${ }^{2}$ Assistant Professor, Department of Anaesthesiology, FH \\ Medical College, Tundla, India.
}

\section{Abstract}

Background: To facilitate tracheal intubation, intubating laryngeal mask airway(ILMA) was designed specifically. A relatively new supraglottic airway device, air-Q ILA is an alternative to ILMA to facilitate endotracheal intubation. Considering advantages of air-Q over ILMA are that the breathing tube of the device is shorter, wider and due to removable connector, a standard e Parker Flex Tip tracheal tube (product of Parker Medical Company) has a curved, centered, flexible and tapered distal tip that is designed to facilitate easy, rapid and nontraumatic intubation. It has double murphy eyes with an anterior curvature and a posterior opening bevel. It is designed so that the posterior bevel will decrease the incidence of the tube catching at the anterior or the lateral laryngeal structures during tracheal intubation. Subjects and Methods: This is a randomized, single-blind study. Total of 100 patients of either sex aged 18-60 years belonging to American Society of Anaesthesiologists (ASA) physical status I or II scheduled for elective surgery under general anesthesia with endotracheal intubation were included in the study and the patients with respiratory or pharyngeal pathology, mouth opening $<2.5 \mathrm{~cm}$, body mass index $\geq 35 \mathrm{~kg} / \mathrm{m} 2$, pregnancy and anticipated difficult airway were excluded from the study. The duration of the study was one year. The ethical clearance was taken from the institutional ethical committee. Written informed consent from all participants was obtained for participation in the study. Results: A total of 100 patients were allocated for the study. The insertion of the airway device was successful in all the patients of group 1 . So, 50 patients were analysed for intubation in group 1. Air-Q ILA could not be inserted and resulted in failure in two cases. Hence, 48 patients were analysed statistically for intubation in group 2. The two groups were comparable with respect to age, weight and sex distribution. The mean age of patients in group 1 was $40.00 \pm 10.76$ years and in group 2 it was $40.56 \pm 11.0$ years $(\mathrm{P}=0.651)$. There were 30 females and 20 males both in group 1 and group $2(\mathrm{P}=1.000)$. The mean weight of patients in group 1 was $60.34 \pm 8.06 \mathrm{~kg}$ and in group $2 \mathrm{was} 60.10 \pm$ $10.05 \mathrm{~kg}(\mathrm{P}=0.924)$. Conclusion: The overall success rate using Parker Flex Tip tube was more with ILMA (99\%) as compared to air-Q ILA (78\%). It can be further suggested that Parker Flex Tip tube can be used as an alternative to silicone tube with ILMA, but more multicentre studies are required over larger populations to evaluate the utility of Parker Flex Tip tube with air-Q ILA.

Keywords: Endotracheal Intubation, Parker Flex Tip Tube, Laryngeal Mask Airway, Manoeuvres.

Corresponding Author: Dr. Rakesh Kumar Gupta, Assistant Professor, Department of Anaesthesiology, FH Medical College, Tundla, India.

\section{Introduction}

Airway management is a difficult task for anaesthesiologists. For anaesthesiologists, good practice and familiarity with a variety of airway techniques and devices are essential. Supraglottic airway devices (SADs) have been introduced in clinical practice in the last few years, which has been shown great importance for patients with difficult tracheal intubation or where intubation is impossible. ${ }^{[1]}$ To facilitate tracheal intubation, intubating laryngeal mask airway (ILMA) was designed specifically. A relatively new supraglottic airway device, air-Q ILA is an alternative to ILMA to facilitate endotracheal intubation. Considering advantages of air-Q over ILMA are that the breathing tube of the device is shorter, wider and due to removable connector, a standard e Parker Flex Tip tracheal tube (product of Parker Medical Company) has a curved, centered, flexible and tapered distal tip that is designed to facilitate easy, rapid and non-traumatic intubation. It has double murphy eyes with an anterior curvature and a posterior opening bevel. It is designed so that the posterior bevel will decrease the incidence of the tube catching at the anterior or the lateral laryngeal structures during tracheal intubation. ${ }^{[2]}$ Manufacturers recommend the use of polyvinyl chloride (PVC) tubes for intubation through air-Q ILA. Val dfr r5 various studies have been conducted using ILMA and air-Q as a conduit for endotracheal intubation..$^{[2-5]}$ The endotracheal tube (ETT) can also be easily placed. ${ }^{[2]}$ There is only one study in literature in which Parker Flex Tip tube was used for intubation through ILMA. The study was conducted by Kanazi et al. who compared silicone wire-reinforced tube with the Parker Flex Tip tube and conventional PVC tube for tracheal intubation through ILMA. ${ }^{[3]}$ This prompted us to undertake this prospective randomised study comparing ILMA and air-Q ILA for intubation using Parker Flex Tip tube. Parker Flex Tip tube can be a cheap alternative to 
recommended silicone wire-reinforced tube for ILMA. But there is no study in the literature regarding usage of Parker Flex Tip tube through air-Q for which conventional PVC tube is recommended. The primary objective was to compare ILMA and air-Q ILA for intubation using Parker Flex Tip tube with regards to the overall success rate. Secondary objectives were a number of attempts for tube placement, insertion time for the tracheal tube, maneuvers required during insertion of ETT, ease of placement of tracheal tube and total time are taken for successful intubation.

\section{Subjects and Methods}

This is a randomised single-blind study. Total of 100 patients of either sex aged 18-60 years belonging to American Society of Anaesthesiologists (ASA) physical status I or II scheduled for elective surgery under general anaesthesia with endotracheal intubation were included in the study and the patients with respiratory or pharyngeal pathology, mouth opening $<2.5 \mathrm{~cm}$, body mass index $\geq 35 \mathrm{~kg} / \mathrm{m} 2$, pregnancy and anticipated difficult airway were excluded from the study. The duration of the study was one year. The ethical clearance was taken from the institutional ethical committee. Written informed consent from all participants was obtained for participation in the study. All the patients were examined during the preoperative visit a day prior to surgery and subjected to a detailed clinical history and complete general physical as well as systemic examination. Routine investigations such as hemoglobin, bleeding time, clotting time and urine examination were carried out in all the patients as per institute protocol. Other investigations were carried out as per requirement.

The purpose and protocol of the study were explained to the patients. Patients were kept fasting for $6 \mathrm{~h}$ prior to the scheduled time of surgery. They were premedicated with tablet alprazolam $0.25 \mathrm{mg}$ and tablet ranitidine $150 \mathrm{mg}$ night before and in the morning $2 \mathrm{~h}$ before surgery. In the operating room, all standard monitoring, including heart rate, ECG, non-invasive blood pressure (NIBP) and pulse oximetry $(\mathrm{SpO} 2)$ were established and baseline readings were recorded. Patients were randomly allocated to one of the two groups using a computer-generated sequence of random numbers. In group $1(\mathrm{n}=50)$, blind intubation through ILMA was done using Parker Flex Tip tube and in group $2(\mathrm{n}=50)$, blind intubation through air-Q ILA was done using Parker Flex Tip tube. A maximum of three attempts was considered for intubation. If a maximum of three attempts, intubation was successful, it was taken as a success. In three attempts, if intubation was not successful, it was considered as a failure of intubation. Insertion time for the tracheal tube (TT) was taken from the moment of picking up the tracheal tube until confirmation of correct placement by capnography. If no capnograph was detected, the tracheal tube was removed and reinserted using maneuver. The time of the second and third attempts was similarly recorded. The total time taken for successful intubation was taken as time from picking up the airway device till the removal of the device from the oral cavity after correct placement of TT and was the sum of various times that is TD + TT + TR.

Grossly visible blood on airway device as evidence of trauma was noted after the removal of the airway device. Complications such as sore throat, hoarseness of voice and dysphagia were recorded after $1 \mathrm{~h}$ of shifting of the patient to post-anesthesia care unit in both the groups by the data collector. Statistical testing was conducted with the statistical package for the social science system version SPSS 17.0. Continuous variables were presented as mean \pm SD and categorical variables were presented as absolute numbers and percentages. The comparison of normally distributed continuous variables between the groups was performed using Student's t-test. Nominal categorical data between the groups were compared using the Chi-squared test. P-value $<0.05$ was considered statistically significant.

\section{Results}

Table1: Success rate of intubation

\begin{tabular}{|l|l|l|l|}
\hline Intubation success & $\begin{array}{l}\text { Group } \\
(\mathbf{n = 5 0 )}\end{array}$ & $\begin{array}{l}\text { Group } \\
(\mathbf{n = 4 8})\end{array}$ & $\mathbf{P}$ \\
\hline Yes & $48(96 \%)$ & $39(78 \%)$ & 0.024 \\
\hline Failure & $2(4 \%)$ & $9(18 \%)$ & \\
\hline $\begin{array}{l}\text { No of attempts for successful } \\
\text { intubation }\end{array}$ & & & \\
\hline 1st attempt & $43(86 \%)$ & $32(64 \%)$ & 0.090 \\
\hline 2nd attempt & $3(6 \%)$ & $6(12 \%)$ & \\
\hline 3rd attempt & $2(4 \%)$ & $1(2 \%)$ & \\
\hline Insertion time of ETT & & & \\
\hline TT (sec) & $21.80 \pm 10.72$ & $20.30 \pm 9.82$ & 0.461 \\
\hline
\end{tabular}

Table 2: Manoeuvres required

\begin{tabular}{|l|l|l|l|}
\hline Manoeuvres & $\begin{array}{l}\text { Group } \\
(\mathbf{n = 5 0 )}\end{array}$ & $\begin{array}{l}\text { Group } \\
(\mathbf{n = 4 8})\end{array}$ & $\mathbf{P}$ \\
\hline Yes & $5(10 \%)$ & $14(28 \%)$ & 0.024 \\
\hline No & $45(90 \%)$ & $34(68 \%)$ & \\
\hline Ease of intubation & & & \\
\hline Easy & $44(88 \%)$ & $34(68 \%)$ & 0.044 \\
\hline Difficult & $5(10 \%)$ & $6(12.0 \%)$ & \\
\hline Failure for & $1(2 \%)$ & $8(16.0 \%)$ & \\
\hline $\begin{array}{l}\text { Total time taken } \\
\text { successful intubation }\end{array}$ & & & \\
\hline Total time(s) & $62.76 \pm 17.84$ & $65.12 \pm 18.73$ & 0.524 \\
\hline
\end{tabular}

A total of 100 patients were allocated for the study. The insertion of the airway device was successful in all the patients of group 1. So, 50 patients were analysed for intubation in group 1. Air-Q ILA could not be inserted and resulted in failure in two cases. Hence, 48 patients were analysed statistically for intubation in group 2. The two groups were comparable with respect to age, weight and sex distribution. The mean age of patients in group 1 was $40.00 \pm$ 10.76 years and in group 2 it was $40.56 \pm 11.0$ years $(\mathrm{P}=$ $0.651)$. There were 30 females and 20 males, both in group 1 and group $2(\mathrm{P}=1.000)$. The mean weight of patients in group 1 was $60.34 \pm 8.06 \mathrm{~kg}$ and in group 2 was $60.10 \pm$ $10.05 \mathrm{~kg}(\mathrm{P}=0.924)$. Intubation was successful in 48 cases $(96 \%)$ in group 1 and 39 cases $(78 \%)$ in group $2(\mathrm{P}=0.024)$ [Table 1]. The odds ratio of failure rate for group 2 as compared to group 1 was 8.39 and it's 95\% CI is $1.222-$ 76.809. Number of attempts for ETT placement $(\mathrm{P}=0.090)$ and insertion time of ETT $(21.80 \pm 10.72 \mathrm{~s}$ in group $1 \mathrm{vs}$ $20.30 \pm 9.82 \mathrm{~s}$ in group $\mathrm{B})[\mathrm{P}=0.461]$ were comparable in both the groups [Table 1]. Manoeuvres for intubation were used in $10.0 \%$ patients in group 1 while it was used in $28.0 \%$ patients in group $2(\mathrm{P}=0.024)$ [Table 2]. Intubation was 
significantly easy in group $1(88.0 \%)$ as compared to group 2 $(68.0 \%)(\mathrm{P}=0.044)$ [Table 2]. Total time taken for successful intubation was comparable in both the groups $(62.76 \pm 17.84 \mathrm{~s}$ in group $1 \mathrm{vs} 65.12 \pm 18.73 \mathrm{~s}$ in group 2$)(\mathrm{P}$ $=0.524)[$ Table 2].

\section{Discussion}

The overall success rate of intubation was significantly more in the ILMA group as compared to the air-Q ILA group [Table 1]. The present study is in accordance with different studies though both these authors used manufacturerrecommended ETT through the study devices. ${ }^{[2,6]}$ The success rate after the first attempt of successful intubation via an ILMA using the silicone wire-reinforced ETT, Parker Flex Tip tube and PVC tube were 90\%, 54\% and 48\%, respectively in a study. ${ }^{[3]}$ These authors observed that after manipulation, the success rate did not change for silicone wire-reinforced tube, whereas it increased in Parker Flex Tip tube and PVC ETT to $86 \%$ and $57 \%$, respectively. ${ }^{[3]}$ The result of the present study is in contrast to a study in which authors observed an overall better success rate for intubation with air-Q ILA as compared to ILMA [(96.0\%) vs $(91.6 \%){ }^{.7]}$ These authors used standard PVC ETT through air-Q ILA in case of failure of intubation in the first attempt, which might be the reason for the increased success rate with this device. In the present study, the mean time required for ILMA insertion was less as compared to air-Q ILA. The results of the present study are similar to different studies in terms of time taken for device insertion. ${ }^{[5,8]}$ However, these results are different from studies in which very little time was observed with air-Q ILA as compared to the ILMA group. ${ }^{[9,10]}$ Less time was taken for air-Q ILA insertion as compared to ILMA by these authors might be due to the use of tongue depressor for air-Q ILA insertion, which created adequate space for the insertion of air-Q ILA leading to a lesser time.

In the present study, a number of attempts for intubation were comparable in both the groups [Table 1]. Comparable results were observed by various authors regarding the number of attempts for intubation though most of the authors used the manufacturer's recommended ETT via the study devices. ${ }^{[5,9,10]}$ ILMA was found to be better than air-Q ILA for intubation. ${ }^{[8]}$ In their study, intubation was done with reinforced silicone tube through ILMA and conventional ETT was used via air-Q ILA and difference was found to be statistically significant. These authors postulated that provision of the handle on the ILMA, together with its rigid metal body, allowed maneuverability when aligning its lumen with the tracheal inlet. ${ }^{[8]}$ The result of the present study [Table 1] is similar to different studies regarding the insertion time of intubation. ${ }^{[7,11]}$ Both of these authors used manufacturer-recommended tubes for intubation. Longer time for intubation via ILMA was observed as compared to air-Q ILA in a study. ${ }^{[11]}$ This might be due to the fact that unlike the present study, these authors used fibreoptic for intubation through both the groups and duration of insertion of the endotracheal tube were calculated from the time fibreoptic entered the device until the anaesthesia circuit was reconnected to the tracheal tube. Statistically longer time was observed with air-Q ILA as compared to ILMA for intubation in another study. ${ }^{[5]}$ The difference observed by these authors can be due to the usage of manufacturerrecommended ETT in their studies as compared to the use of Parker Flex Tip tube in the present study. Intubation was significantly easy in group A $(89.1 \%)$ as compared to group B $(72.2 \%)$ in the present study [Table 2]. These results are in agreement with the results of a study in which authors observed more ease of insertion via ILMA as compared to air-Q ILA though they used conventional PVC ETT with airQ ILA and reinforced silicone ETT with ILMA. ${ }^{[8]}$ In contrast, in another study, the same ease of intubation was observed between ILMA and air-Q ILA in which standard recommended ETT was used. ${ }^{[9]}$ Regarding the total time taken for intubation, the result of the present study [Table 2] is similar to a study even though these authors used silicone ETT for intubation through ILMA. ${ }^{[7]}$ In contrast, more time was taken for successful intubation via ILMA as compared to air-Q ILA. ${ }^{[9]}$ Authors stated that as they used Chandy's maneuver while intubation through ILMA, that might have resulted in an increase in intubation time via ILMA, resulting in an increase in total intubation time.

Overall, the number of patients with air-Q ILA had an increased rate of complications as compared to ILMA except for dysphagia, which was seen only in one patient that too with ILMA Results are consistent with findings of various authors. ${ }^{[5,7,10,11]}$ There are manufacturer recommendations for ILMA and air-Q ILA. Many a time, ETTs either due to its cost factor or other reasons are not available with the users. Parker Flex Tip tube introduced by J D Parker has certain advantages like it has a flexible, curved, centred, tapered distal tip that facilitates rapid, easy and non-traumatic intubation and is also cost-effective. There are a few limitations to the present study. Patients with normal airways were included in this study. Hence the results may differ in patients with difficult airways. Another limitation was the inability to blind the observer and data collector. Further, airway morbidity should have been assessed for a longer duration. In this study, the only first-hour parameter was assessed which also adds to the limitation of the study.

\section{Conclusion}

In the present study the overall success rate using Parker Flex Tip tube was more with ILMA $(99 \%)$ as compared to air-Q ILA (78\%). It can be further suggested that Parker Flex Tip tube can be used as an alternative to silicone tube with ILMA but more multicentre studies are required over larger populations to evaluate the utility of Parker Flex Tip tube with air-Q ILA.

\section{References}

1. Robak O, Leonardelli M, Zedtwitz-Liebenstein K, Rutzler K, Schuster E, Vaida $\mathrm{S}$ et al. Feasibility and speed of insertion of seven supraglottic airway devices under simulated airway conditions. CJEM. 2012;14:330-334.

2. Karim YM, Swanson DE. Comparison of blind tracheal intubation through the intubating laryngeal mask airway (LMA Fastrach ${ }^{\mathrm{TM}}$ ) and the AIR-Q ${ }^{\mathrm{TM}}$ Anaesthesia. 2011;66:185-90.

3. Kanazi GE, El-Khatib M, Nasr VG, Kaddoum R, Al-Alami A, Baraka AS, et al. A comparison of a silicon wire reinforced tube with the Parker and polyvinyl chloride tubes for tracheal intubation through an 
intubating laryngeal mask airway in patients with normal airways undergoing general anaesthesia. Anesth Analg. 2008;107:994-997.

4. Ebeid RS, Ali MZ, Khafagy HF, Samhan YM. Bougie assisted endotracheal intubation using the Air-Q $\mathrm{Q}^{\mathrm{TM}}$ intubating laryngeal airway: A prospective randomized clinical study. Egypt J Anaesth. 2017;33:107-12.

5. Siamdoust SS, Rokhtabnak F, Motlagh SD, Rahimzadeh P, Hassani V, Farnaghizad M. Comparison of the success rate of intubation between the LMA fastrach and Air Q-ILA methods in patients undergoing elective surgery during general anaesthesia. Anesth Pain Med. 2018;8:63424-63429.

6. Neoh EU, Choy YC. Comparison of the air-Q ILA ${ }^{\mathrm{TM}}$ and the LMA fastrach $^{\mathrm{TM}}$ in airway management during general anaesthesia. South Afr J Anaesth Analg. 2012;18:150-155.

7. Malhotra SK, Bharath KV, Saini V. Comparison of success rate of intubation through air-Q with ILMA using two different endotracheal tubes. Indian J Anaesth. 2016;60:242-247.

8. Shamaa MA, Alia DA, El-sayed M. Intubating Laryngeal mask airway and air- $\mathrm{Q}$ for blind tracheal intubation. Res Opin Anesth Intensive Care. 2015;2:101-110.

9. Abdel-Halim TM, Anin MAAE, Elgoushi MM, Afifi MG, Atwa HS. Comparative study between Air-Q and intubating laryngeal mask airway when used as conduit for fiber-optic. Egypt J Anaesth. 2014;30:107113.

10. Bari N, Haleem S, Varshney VK, Fatima N. Second generation extraglottic airway devices (AMBU, Air-Q and I-LMA): A comparative study to assess the relative success rate in first attempt and safety for blind tracheal intubation. Cent J ISA. 2017;1:49-56.

11. Badawi R, Mohamed NN, Abd Al-Haq MM. Tips and tricks to increase the success rate of blind tracheal intubation through the Air- $\mathrm{Q}^{\mathrm{TM}}$ vs the Intubating Laryngeal Mask Airway. Egypt J Anaesth. 2014;30:59-65.

Copyright: (C) the author(s), 2020. It is an open-access article distributed under the terms of the Creative Commons Attribution License (CC BY 4.0), which permits authors to retain ownership of the copyright for their content, and allow anyone to download, reuse, reprint, modify, distribute and/or copy the content as long as the original authors and source are cited.

How to cite this article: Masih SM, Gupta RK. A Comparitive Study of Laryngeal Mask Airway and Air-Q Intubating Laryngeal Airway Using Parker Flex Tip Tube. Acad. Anesthesiol. Int. 2020;4(1):149-152.

DOI: dx.doi.org/10.21276/aan.2020.5.1.30

Source of Support: Nil, Conflict of Interest: None declared. 